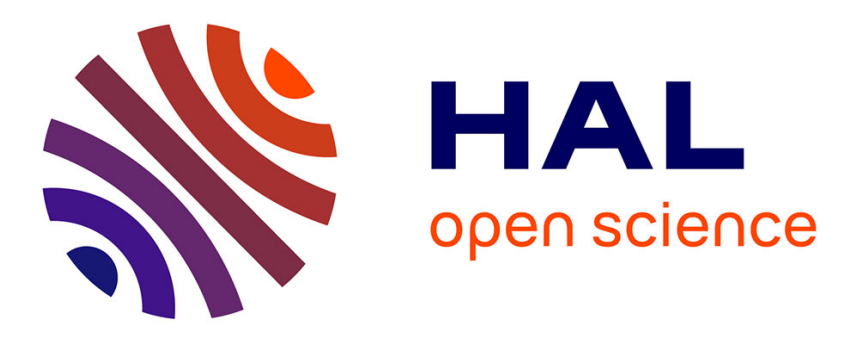

\title{
Fractional order model reference adaptive control for SCARA robot trajectory tracking
}

\author{
Yassine Bensafia, Samir Ladaci, Khatir Khettab, Ahmed Chemori
}

\section{To cite this version:}

Yassine Bensafia, Samir Ladaci, Khatir Khettab, Ahmed Chemori. Fractional order model reference adaptive control for SCARA robot trajectory tracking. International Journal of Industrial and Systems Engineering, 2018, 30 (2), pp.138-156. 10.1504/IJISE.2018.094839 . lirmm-01887395

\section{HAL Id: lirmm-01887395 \\ https://hal-lirmm.ccsd.cnrs.fr/lirmm-01887395}

Submitted on 4 Oct 2018

HAL is a multi-disciplinary open access archive for the deposit and dissemination of scientific research documents, whether they are published or not. The documents may come from teaching and research institutions in France or abroad, or from public or private research centers.
L'archive ouverte pluridisciplinaire HAL, est destinée au dépôt et à la diffusion de documents scientifiques de niveau recherche, publiés ou non, émanant des établissements d'enseignement et de recherche français ou étrangers, des laboratoires publics ou privés. 


\title{
Fractional order model reference adaptive control for SCARA robot trajectory tracking
}

\author{
Yassine Bensafia \\ Electrical Engineering Department, \\ Bouira University, \\ Bouira, 10000, Algeria \\ Email: bensafiay@yahoo.fr \\ Samir Ladaci* \\ Department of EEA, \\ National Polytechnic School of Constantine, \\ Ali Mendjli, Constantine 25000, Algeria \\ and \\ Department of Electronics, \\ SP-Lab Laboratory, \\ University of Constantine 1, \\ Constantine 25000, Algeria \\ Email: samir_ladaci@yahoo.fr \\ *Corresponding author
}

\section{Khatir Khettab}

Department of Electrical Engineering, University of M'sila,

M'sila 28000, Algeria

Email: zoubirhh@yahoo.fr

\author{
Ahmed Chemori \\ LIRMM - CNRS/Univ. Montpellier 2. 161, \\ rue Ada 34095 Montpellier, France \\ Email: chemori@lirmm.fr
}

\begin{abstract}
This paper proposes a new control strategy to the problem of trajectory tracking of SCARA robotic manipulator system by using a fractional order model reference adaptive controller (FMRAC) for sufficiently smooth trajectories. Over the few last years the idea of introducing fractional calculus and systems in adaptive control has found a great interest, for the benefits one can win in the performances given by such systems. The main contribution of this paper, is to show that the proposed fractional adaptive controller is able to reduce the delay time and the overshoot existing in classical control approach. Simulation results illustrate the effectiveness of the proposed control approach comparatively to the classical integer order one.
\end{abstract}


Keywords: fractional adaptive control; model reference adaptive control; MRAC; SCARA robot; trajectory tracking; approximation methods.

Reference to this paper should be made as follows: Bensafia, Y., Ladaci, S., Khettab, K. and Chemori, A. (2018) 'Fractional order model reference adaptive control for SCARA robot trajectory tracking', Int. J. Industrial and Systems Engineering, Vol. 30, No. 2, pp.138-156.

Biographical notes: Yassine Bensafia received his Engineering and Magister degrees in Electrical Engineering from the University of Béjaia in 2003 and 2006, respectively. He received his Science Doctorate in Automatic Control from the Department of Electrical Engineering, University of the 20th August 1955 of Skikda, Algeria in May 2016. Since 2015, he is with the University of Bouira as an Assistant Professor. His research interests include fractional systems control, adaptive control and robust control.

Samir Ladaci is a Full Professor at the EEA Department of the National Polytechnic School of Constantine, Algeria. He received his State Engineer degree in Automatics in 1995 from the National Polytechnic School of Algiers, Algeria and Magister degree in Industrial Automation from Annaba University, Algeria in 1999. He received his PhD (Doctorat en Science) and the Habilitation (HDR) degrees from the Department of Electronics, Mentouri University of Constantine, Algeria in 2007 and 2009, respectively. From 2001 to 2013, he was with the Department of Electrical Engineering at the University of Skikda, Algeria as an Assistant Professor. He has been also the Head of Control Research Team at the SP-Lab Laboratory, University of Mentouri Constantine since 2014. He has more than 80 papers in journals and international conferences, and supervises many $\mathrm{PhD}$ theses. His current research interests include fractional order systems and control, fractional adaptive control, robust control and identification.

Khatir Khettab graduated from Ferhat Abbes University of Sétif (UFAS), Algeria in 2001. He received his MSc from UFAS in 2005, Algeria. He received his $\mathrm{PhD}$ in Automatic Control from the University of the 20th August 1955 of Skikda, Algeria in June 2016. He is an Assistant Professor at the Mohamed Boudiaf University of M'sila, Algeria. His research interests include robotics and automation, especially the fractional systems control, chaos synchronisation and fractional adaptive intelligent control.

Ahmed Chemori received his $\mathrm{MSc}$ and $\mathrm{PhD}$ in Automatic Control from the Grenoble Institute of Technology, Grenoble, France in 2001 and 2005, respectively. He was a Post-Doctoral Fellow with the Automatic Control Laboratory of Grenoble, Grenoble in 2006. He is currently a Tenured Research Scientist in Automation and Robotics with the Laboratoire d'Informatique, de Robotique et de Microélectronique de Montpellier, Montpellier, France. His current research interests include adaptive and predictive control and their applications in robotics. 


\section{Introduction}

Modern industry depends increasingly on robotic manipulators for their ability of improving the product quality and increasing the production efficiency. Industrial tasks needing more and more accuracy in trajectory tracking involved a great research effort on motion control systems design (Borenstein and Koren, 1987). Adaptive control techniques have been intensively used for robotic systems as the problem of controlling the motion of rigid-link manipulators which require precise knowledge of the complete manipulator dynamic model for implementation suffer from the lack of accuracy of joint velocity measurements (Colbaugh et al., 1996; Pagilla and Tomizuka, 2001; Alonge et al., 2003; Yildirim, 2005; Yanling, 2015).

Model reference adaptive control (MRAC) remains one of the most popular approaches of adaptive control, regarding its simplicity of implementation and its high efficiency (Tung et al., 2000; Cortesão, 2009). In this adaptive system, the desired performance is specified by a chosen reference model. The difference between the plant output and the reference model output is used to adjust the controller parameters. Its ability to deal with unknown or slowly varying plants attracted many researchers, who tried to increase the MRAC control scheme robustness in order to better deal with industrial application problems in presence of noises and disturbances. Various modified approaches were proposed for this aim (Chien et al., 1996; Makoudi and Radouane, 1996).

In this paper we propose a fractional order MRAC approach (Ladaci and Charef, 2006; Bensafia and Ladaci, 2011) for trajectory tracking of a robot manipulator. The proposed controller introduces in classical MRAC scheme a fractional order systems as referential dynamics in order to improve the global control system behaviour. Since a decade and the pioneering works on FMRAC design (Hadjili and Abida, 1994), many variants of FMRAC control scheme have been developed (Vinagre et al., 2002; Ladaci et al., 2009; Shi et al., 2014; Wei et al., 2015).

This control approach has been applied to different types of processes such as a robot arm (Ladaci and Charef, 2002), a DC motor (Ladaci and Charef, 2006), a hydraulic driven flight motion simulator (Ma et al., 2009), an isotope separation plant (Dumitrache et al., 2012), an automatic voltage regulator (Aguila-Camacho and Duarte-Mermoud, 2013).

In this paper the trajectory tracking control of a SCARA type robot is considered. SCARA manipulators are widely used in industrial factories and academic laboratories, gathering various research works for different control strategies (Garg, 1991; Whitcomb et al., 1993; Visioli and Legnani, 2002; Roudbari, 2010).

Some fractional order control schemes have been already proposed for the problem of robotic manipulators control for trajectory tracking: Delavari et al. (2010) proposed a fractional adaptive PID controller for a robot manipulator showing that the trajectory of the robot converges to the desired one asymptotically. Marcos et al. (2008) studied the fractional chaotic dynamics of robots with kinematical redundancy. Whereas, Dumlu and Erenturk (2002) introduced a fractional-order $\mathrm{PI}^{\lambda} \mathrm{D}^{\mu}$ controller to determine the control action for 3-degrees-of-freedom parallel manipulator and were able to improve the results obtained with the classical PID controller.

The main contribution of this work is the use the fractional model reference adaptive control (FMRAC) to determine the control action for trajectory tracking of a SCARA type manipulator. This control application is a major challenge as the trajectory tracking 
control of industrial parallel mechanisms involves high speed, high acceleration, and high accuracy.

This paper is structured as follows: Section 2 is an background on MRAC and MIT rule approach. Section 3 presents fractional order systems and their approximation methods with rational transfer functions. The FMRAC with application time varying reference trajectory tracking in robotics are given in Section 4. Section 5 presents the simulation results of the proposed fractional adaptive controller for SCARA robot. Finally, some concluding remarks with future work are presented in Section 6.

\section{Background on MRAC: description and limitations}

\subsection{MRAC description}

The parallel structure (Figure 1) is the most famous MRAC structure, called the method of the output error; this approach involves plant model identification (Johnson et al., 1984; Landau, 1979).

Figure 1 Parallel structure of MRAC

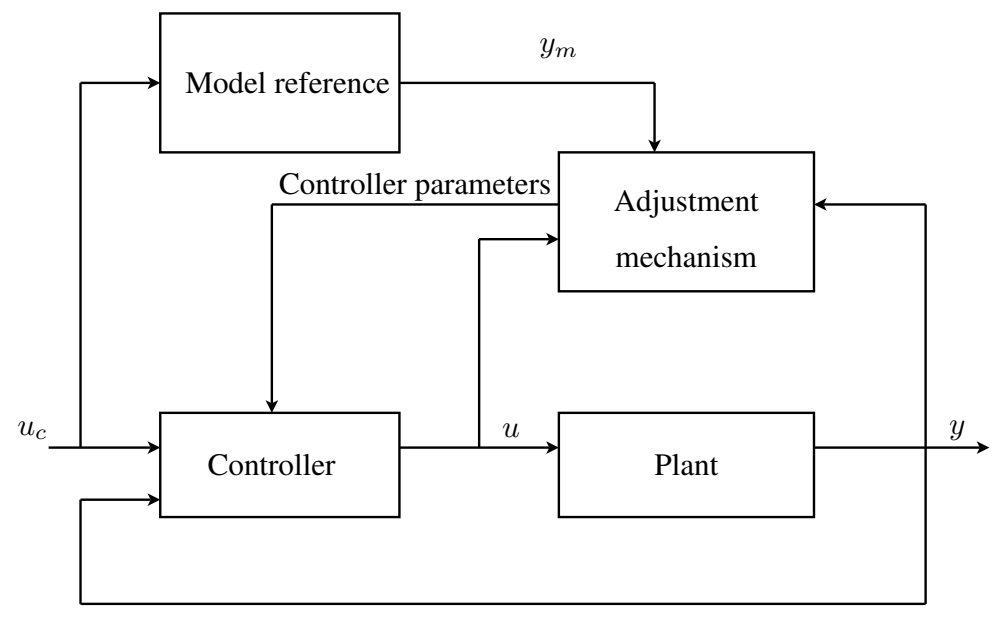

Consider an single input, single output system, which can be a model of continuous time or discrete-time model:

$$
y(t)=\frac{B}{A} u(t)
$$

where $u$ is the control signal and $y$ is the output signal. The symbols $A$ and $B$ denote polynomials in the differential operator $p$. It is assumed that the degree level $\operatorname{deg}(A) \geq \operatorname{deg}(B)$, the system is causal.

We assume that the performance specifications are given in terms of a reference model of the form,

$$
y_{m}(t)=\frac{B_{m}}{A_{m}} u_{c}(t)
$$


where $u_{c}$ is the reference signal and $y_{m}$ is the desired model output signal. $A_{m}$ and $B_{m}$ are polynomials in the differential operator $p$.

The general linear control law represented in Figure 2, is described as:

$$
R u=T u_{c}-S y
$$

where $R, S$, and $T$ are polynomials. This control law represents a negative feedback with the transfer operator $-S / R$ and a feedforward with the transfer operator $T / R$. It thus has two degrees of freedom.

Figure 2 Closed-loop system with a linear regulator

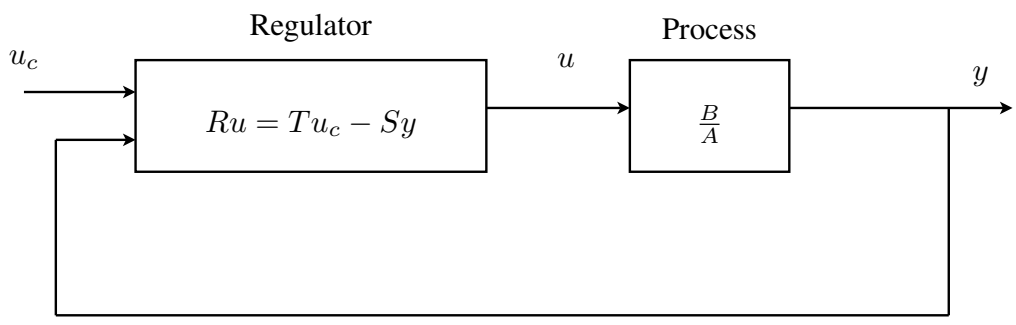

The gradient approach of MRAC is based on the assumption that the parameters change more slowly than the other variables in the system. This assumption, which admits a quasi-stationary treatment, is essential for the computation of the sensitivity derivatives that are needed in the adaptation (Makoudi and Radouane, 1996; Åström and Wittenmark, 1995).

Let $e$ denote the error between the system output $y$ and the reference output $y_{m}$, and let $\theta$ denote the parameters' vector to be updated. By using the criterion:

$$
J(\theta)=\frac{1}{2} e^{2}
$$

the adjustment rule for changing the parameters in the direction of the negative gradient of $J$ is,

$$
\frac{d \theta}{d t}=-\gamma \frac{\delta J}{\delta \theta}=-\gamma e \frac{\delta e}{\delta \theta}
$$

The derivative $\frac{\delta e}{\delta \theta}$, i.e., the sensitivity derivative of the system, can be evaluated under the assumption that $\theta$ is constant (Landau, 1979).

The control law is given by the following equation,

$$
u=\theta^{T} \varphi
$$

where $\varphi$ is the regression vector or measurement vector such that,

$$
\varphi=-\frac{\delta e}{\delta \theta}
$$




\subsection{Limitations}

Let us study a simulation example to illustrate the limitations of this control scheme in case of a time varying reference.

Consider the system described by the following equation,

$$
G(s)=\frac{y(s)}{u(s)}=\frac{2 s+8}{s^{2}-3 s-2}
$$

The referential model is defined by:

$$
G_{m}(s)=\frac{y_{m}(s)}{u_{c}(s)}=\frac{1}{0.2 s+1}
$$

The control objective is to minimise the error:

$$
e=y-y_{m}
$$

The recurrence equation of the system described above which is obtained after the discretisation (with the sampling period $T=0.04 \mathrm{sec}$.) is given by:

$$
y(k+2)=2.131 y(k+1)-1.127 y(k)+0.09171 u(k+1)-0.07811 u(k)
$$

The recurrence equation of the reference model (9) which is obtained after the discretisation $(T=0.04)$ is given by:

$$
y_{m}(k+1)=0.8187 y_{m}(k)+0.1813 u_{c}(k)
$$

Let $k, l$ and $m$ be respectively the degree of the polynomials $R, S$ and $T$, such that Åström and Wittenmark (1995):

$$
\begin{aligned}
k & =\operatorname{deg} R=\operatorname{deg} A_{m}+\operatorname{deg} B-\operatorname{deg} A=1+1-2=0 \\
l & =\operatorname{deg} S=\operatorname{deg} R=0 \\
m & =\operatorname{deg} T=\operatorname{deg} B_{m}=0
\end{aligned}
$$

Therefore, the vector of regulation parameters is:

$$
\theta=\left(s_{0} t_{0}\right)
$$

Let us define the regression vector $\varphi$ as follows,

$$
\begin{aligned}
\varphi^{T} & =-\left[\frac{\delta e}{\delta r_{1}} \frac{\delta e}{\delta r_{2}} \ldots \frac{\delta e}{\delta r_{k}} \frac{\delta e}{\delta s_{0}} \frac{\delta e}{\delta s_{1}} \ldots \frac{\delta e}{\delta s_{l}} \frac{\delta e}{\delta t_{0}} \frac{\delta e}{\delta t_{1}} \ldots \frac{\delta e}{\delta t_{m}}\right] \\
& =\frac{b_{0}}{A_{o} A_{m}}\left[s^{k-1} u \ldots u s^{l} y \ldots y-s^{m} u_{c} \ldots-u_{c}\right] \\
& =\frac{b_{0}}{A_{o} A_{m}}\left[y-u_{c}\right]
\end{aligned}
$$


such that $b_{0}=1$ and the $A_{o}$ the observer polynomial is chosen as $A_{o}=s+1$; thus,

$$
\varphi^{T}=\frac{1}{(s+1)(0.2 s+1)}\left[y-u_{c}\right]
$$

which is equivalent in the discrete time using the process sampling period $T=0.04 \mathrm{sec}$. to,

$$
\varphi^{T}(k)=\frac{0.003696 z+0.003412}{z^{2}-1.78 z+0.7866}\left[y(k)-u_{c}(k)\right]
$$

giving the following regression,

$$
\begin{aligned}
\varphi^{T}(k+2)= & 1.78 \varphi^{T}(k+1)-0.7866 \varphi^{T}(k) \\
& +[0.003696 y(k+1)+0.003412 y(k) \\
& \left.-0.003696 u_{c}(k+1)-0.003412 u_{c}(k)\right]
\end{aligned}
$$

Using the command law of equation (6), we obtain the system output response shown in Figure 3.

Figure 3 Reference trajectory $y_{m}$ and output trajectory $y$ using the classical MRAC approach (see online version for colours)

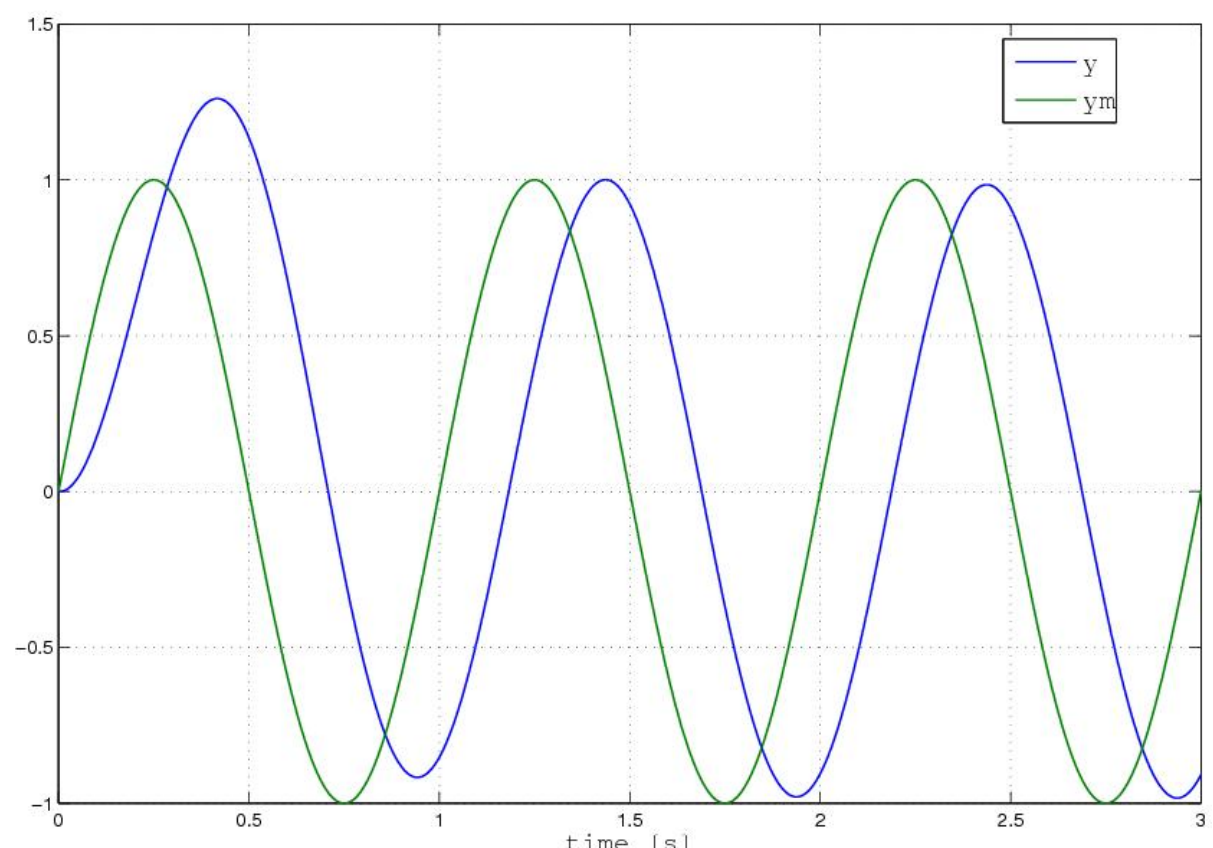

From Figure 3, we remark that the output of the system follows the referential one with the overshoot $D=1.25$ and the delay time $t_{d}=0.21 \mathrm{~s}$, this characteristic presents the major limitation of the MRAC approach in the tracking control strategy.

Besides, as robot systems are strongly nonlinear, the only way to apply this control strategy is to consider sufficiently smooth or slowly varying referential trajectories. 


\section{Fractional order systems}

\subsection{Fractional calculus}

Fractional calculus is a subdivision of calculus theory which generalises the derivative or integral of a function to non-integer order (Oustaloup, 1995). The number of applications where fractional calculus has been used grows rapidly mainly for the reason that these mathematical phenomena allow to describe a real object more accurately than the classical methods. Approximation methods of fractional derivative and integral to rational functions permitted to use very easily fractional order systems in wide areas of applications such as control theory (Sabatier et al., 2003; Ladaci et al., 2008, 2010), economical systems (Dadras and Momeni, 2010), renewable energy (Melício et al., 2010; Neçaibia et al., 2015), vehicle motion systems (Neçaibia et al., 2015b), Spacecraft attitude control (Manabe, 2002), etc.

The generalised fundamental operator which includes the differentiation and integration is given as:

$$
{ }_{a} D_{t}^{\mu}= \begin{cases}\frac{d^{\mu}}{d t^{\mu}} & \mathfrak{R}(\mu)>0 \\ 1 & \mathfrak{R}(\mu)=0 \\ \int_{a}^{t}(d \tau)^{-\mu} & \mathfrak{R}(\mu)<0\end{cases}
$$

where

- $a$ : lower limit of integration.

- $t$ : upper limit of integration.

- $\quad \mu$ : order of fractional differentiation or integration. $\mu$ with negative value indicates integration while $\mu$ with positive value indicates differentiation.

The theory of fractional-order derivative was developed mainly in the 19th century. There are several definitions of fractional order derivative. Two important and widely applied definitions are Riemann-Liouville definition and Grünwald-Letnikov definition which is perhaps the best known due to its most suitability for the realisation of discrete control algorithms (Podlubny, 1999).

The Grünwald-Letnikov definition is expresses as:

$$
{ }_{a} D_{t}^{\mu} f(t)=\lim _{h \rightarrow 0} h^{-\mu} \sum_{r=0}^{\frac{t-a}{h}}(-1)^{r} \frac{\Gamma(\mu+1)}{r ! \Gamma(\mu-r+1)} f(t-r h)
$$

where the binomial coefficients $(r>0)$ are given by:

$$
\left(\begin{array}{c}
\mu \\
0
\end{array}\right)=1, \quad\left(\begin{array}{l}
\mu \\
r
\end{array}\right)=\frac{\mu(\mu-1) \ldots(\mu-r+1)}{r !}
$$

The Riemann-Liouville definition is expresses as:

$$
{ }_{a} D_{t}^{\mu} f(t)=\frac{1}{\Gamma(\eta-\mu)} \frac{d^{\eta}}{d t^{\eta}}\left[\int_{a}^{t} \frac{f(\tau)}{(t-\tau)^{\mu-\eta+1}} d \tau\right]
$$


where:

$$
\Gamma(x)=\int_{t}^{a} y^{\mu-1} e^{-y} d y
$$

$\Gamma($.$) is the Euler's Gamma function.$

For a wide class of functions which appear in real physical and engineering applications, the Riemann-Liouville and the Grünwald-Letnikov definitions are equivalent.

\subsection{Approximation methods of a fractional order transfer function}

Many approximations methods ave been developed in the fractional calculus literature. The most popular are those of Charef Charef et al. (1992) called the singularity function method and Oustaloup's method (Oustaloup et al., 2000). This second approach is a generalised differential action which covers the frequency space, based on a recursive distribution of an infinite number of zeros and negative real poles (to ensure phase behaviour minimum). As part of a realist synthesis (practice) based on a finite number of zeros and poles, it should reduce the differential behaviour of a generalised bounded frequency range, chosen according to the needs of the application.

The method is based on the function approximation from:

$$
H(s)=s^{\alpha}, \quad \alpha \in \mathfrak{R}
$$

By a rational function:

$$
G_{f}(s)=K \prod_{k=1}^{N} \frac{s+\omega_{k}^{\prime}}{s+\omega_{k}}
$$

where the poles, zeros, and gain are evaluated from:

$$
\omega_{k}^{\prime}=\omega_{b} \cdot \omega_{u}^{(2 k-1-\gamma) / N}, \quad \omega_{k}=\omega_{b} \cdot \omega_{u}^{(2 k-1+\gamma) / N}, \quad K=\omega_{h}^{\gamma}
$$

where $\omega_{u}$ is the unity frequencies' gain and the central frequency of a band of frequencies distributed geometrically. We have $\omega_{u}=\sqrt{\omega_{h} \cdot \omega_{b}}$, where $\omega_{h}$ and $\omega_{b}$ are respectively the upper and lower frequencies, $\gamma$ is the order of derivative, and $N$ is the order of the filter.

\section{Fractional model reference adaptive control}

The proposed global control scheme for trajectory tracking control of robot manipulator is based on a position-feedback as illustrated in Figure 4.

It is composed of three parts:

- the robot

- the linearised dynamics expressed in articular space

- the fractional order model reference controller. 
Figure 4 Global control scheme for robot manipulator: FMRAC approach

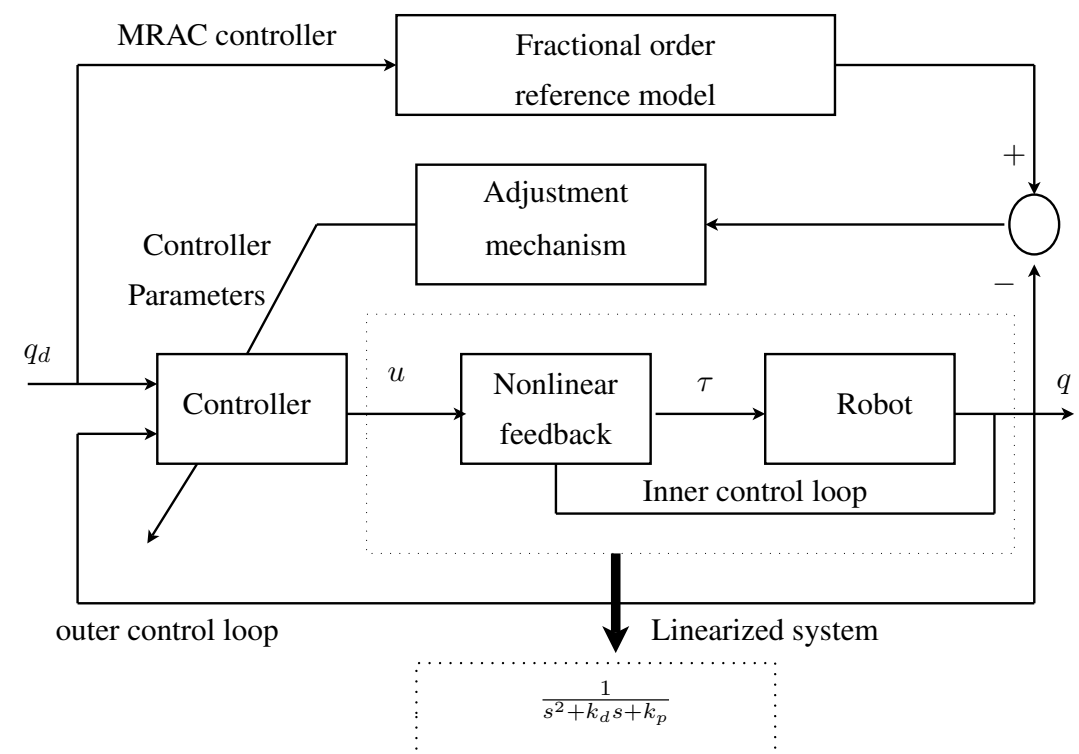

\subsection{Dynamic model of the SCARA robot}

This dynamic model can be written in the following matrix form Amiri et al. (2009):

$$
B(q) \ddot{q}+C(q, \dot{q}) \dot{q}+G(q)=\tau
$$

where

- $\quad B(q) \in \mathfrak{R}^{3} \times \mathfrak{R}^{3}$ is the inertia matrix

- $C(q, \dot{q}) \in \mathfrak{R}^{3}$ is the matrix of the centrifugal and Coriolis terms

- $G(q) \in \mathfrak{R}^{3}$ is the vector of gravitational forces

- $\tau \in \mathfrak{R}^{3}$ is the vector of control inputs (torques generated by the actuators)

- $q=\left(\begin{array}{c}q_{1} \\ q_{2} \\ q_{3}\end{array}\right) \in \mathfrak{R}^{3}$ is the vector of articular positions

- $\quad \dot{q}=\left(\begin{array}{c}\dot{q}_{1} \\ \dot{q}_{2} \\ \dot{q}_{3}\end{array}\right) \in \mathfrak{R}^{3}$ is the vector of articular velocities

- $\quad \ddot{q}=\left(\begin{array}{l}\ddot{q}_{1} \\ \ddot{q}_{2} \\ \ddot{q}_{3}\end{array}\right) \in \mathfrak{R}^{3}$ is the vector of articular accelerations.

\subsection{Linearised model of the SCARA robot}

The linearisation model of the robot with a nonlinear feedback is given by the following equivalent transfer function:

$$
G(s)=\frac{1}{s^{2}+k_{d} s+k_{p}}
$$


where $s$ is the complex variable of the transfer function, $k_{p}$ is the position gain and $k_{d}$ the velocity gain.

\subsection{Fractional order reference model}

The reference model is used to specify the desired performance and to monitor the state of the robot. It is chosen and adjusted in practice according to the operation conditions and the environment (Feng et al., 1994). For the present study we will propose a fractional model reference given by:

$$
G_{m f}(s)=\frac{\omega^{2}}{s^{\alpha}\left(s^{2}+2 \omega \xi s+\omega^{2}\right)}
$$

with $\alpha \in\left[\begin{array}{ll}0 & 1\end{array}\right]$.

\section{Application: trajectory tracking in SCARA robot}

\subsection{Experimental configuration}

This dynamic model can be written in the matrix form (26):

$$
B(q) \ddot{q}+C(q, \dot{q}) \dot{q}+G(q)=\tau
$$

The Dynamical parameters of the SCARA robot are summarised in Table 1.

Table 1 Parameters of SCARA robot

\begin{tabular}{lcccc}
\hline \multirow{2}{*}{ Segment } & Segment & Segment & Segment & Segment \\
& 0 & 1 & 2 & 3 \\
\hline Mass $(\mathrm{kg})$ & $m_{0}=19: 5$ & $m_{1}=8$ & $m_{2}=6$ & $m_{3}=0: 5$ \\
Length $(\mathrm{m})$ & $d_{0}=0: 65$ & $d_{1}=0: 4$ & $d_{2}=0: 3$ & $d_{3}=0: 3$ \\
Inertia $\left(\mathrm{kg} \mathrm{m}^{2}\right)$ & $I_{0}=1: 0.298$ & $I_{1}=0: 16$ & $I_{2}=0: 0.675$ & $I_{3}=0: 0.056$ \\
\hline
\end{tabular}

The reference trajectory is set as follows:

$$
q_{1}=q_{2}=q_{3}=\frac{10 \pi}{180} \sin (2 \pi t)
$$

The integer order model reference $(\alpha=1)$ is given by:

$$
G_{m}(s)=\frac{\omega^{2}}{s\left(s^{2}+2 \omega \xi s+\omega^{2}\right)}
$$

with $\omega=20, \xi=1$.

The fractional model reference is given by (28):

$$
G_{m f}(s)=\frac{\omega^{2}}{s^{\alpha}\left(s^{2}+2 \omega \xi s+\omega^{2}\right)}
$$


with $\omega=20, \xi=1$ and $\alpha=0.3$.

The parameters of the linearised model of the robot are: $k_{p}=2,500$ and $k_{d}=500$.

The reference models are discretised using a sampling period $T=0.04 \mathrm{sec}$.

Now if we reconsider the plant and reference models (1) and (2) in discrete time we have,

$$
A(z) y(k)=B(z) u(k)
$$

and

$$
A_{m}(z) y_{m}(k)=B_{m}(z) u_{c}(k)
$$

We will denote by $\theta(k)$ a vector containing the unknown controller parameters, and by $\varphi(k)$ the regression vector (7) discretised with the sampling constant $T$.

Using a simple approximation of the adaptation rule (5) in its normalised form, we get

$$
\theta(k+1)=\theta(k)-\frac{T \gamma\left(y(k)-y_{m}(k)\right) \varphi(k)}{\epsilon+\varphi(k)^{T} \varphi(k)}
$$

where $\epsilon$ is a positive real.

The adaptive control law (6) is given by,

$$
u(k+1)=\theta^{T}(k+1) \varphi(k)
$$

\subsection{Numerical simulations}

This section presents simulation results of the proposed architecture based on the linearising feedback and the FMRAC controller.

The parameter vector $\theta$ is initiaised as:

$$
\theta_{0}=\left[\begin{array}{llll}
0.0 & 235.2 & 1771.4 & 1771.4
\end{array}\right]^{T} .
$$

The output response and the corresponding torques of the SCARA robot using the classical MRAC controller with the above model and control parameters are shown in Figure 5 and Figure 6 respectively.

From Figure 5, we remark that the system output follows the referential one with an overshoot $D=0.035$ and a delay time $t_{d}=0.14 \mathrm{~s}$, this characteristic presents the most limitation of the MRAC approach in trajectory tracking control.

In order to reduce the delay time between the trajectory of the SCARA robot and the reference trajectory (29), let us use the fractional Model Reference defined above.

The output response of the robot and the corresponding torques using the FMRAC controller for $\alpha=0.7$ are shown in Figure 7 and Figure 8 respectively.

From Figure 7, we remark that the output of the system follows the referential one with very small oscillations comparatively to the integer order case and a reduced delay time of $t_{d}=0.0293 \mathrm{~s}$ with an overshoot $D=0.019$, thus, the system achieved a better asymptotic tracking using a fractional order reference model of order $\alpha=0.7$. 
Figure 5 Articular reference trajectory and robot trajectory using the classical MRAC approach (see online version for colours)
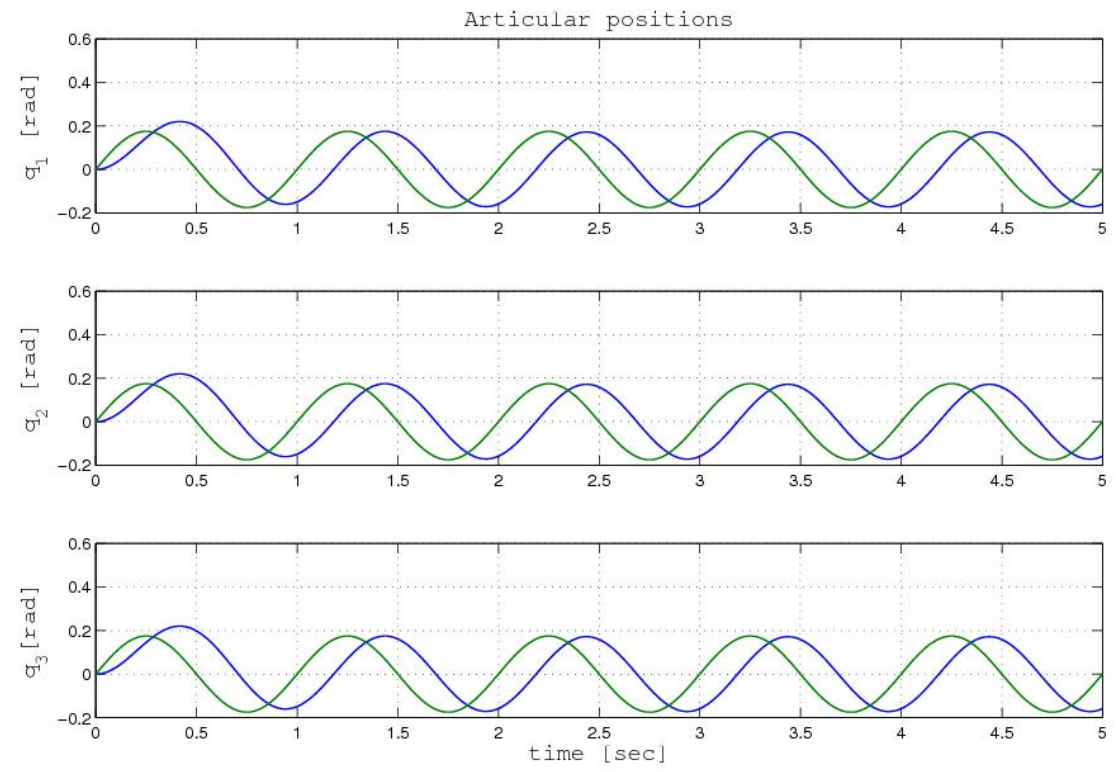

Figure 6 Control torques for the MRAC controller (see online version for colours)
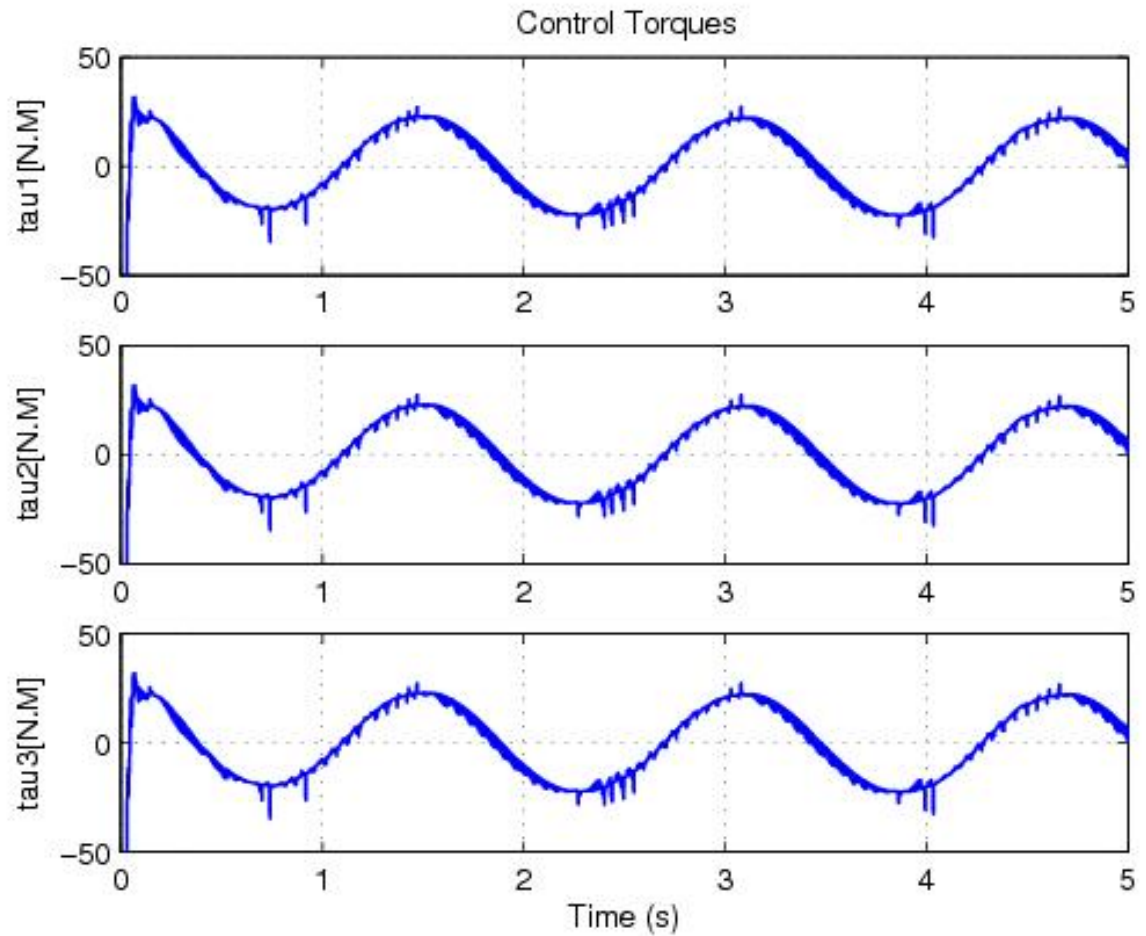
Figure 7 Articular reference trajectory and robot trajectory using the proposed FMRAC approach with $\alpha=0.7$ (see online version for colours)
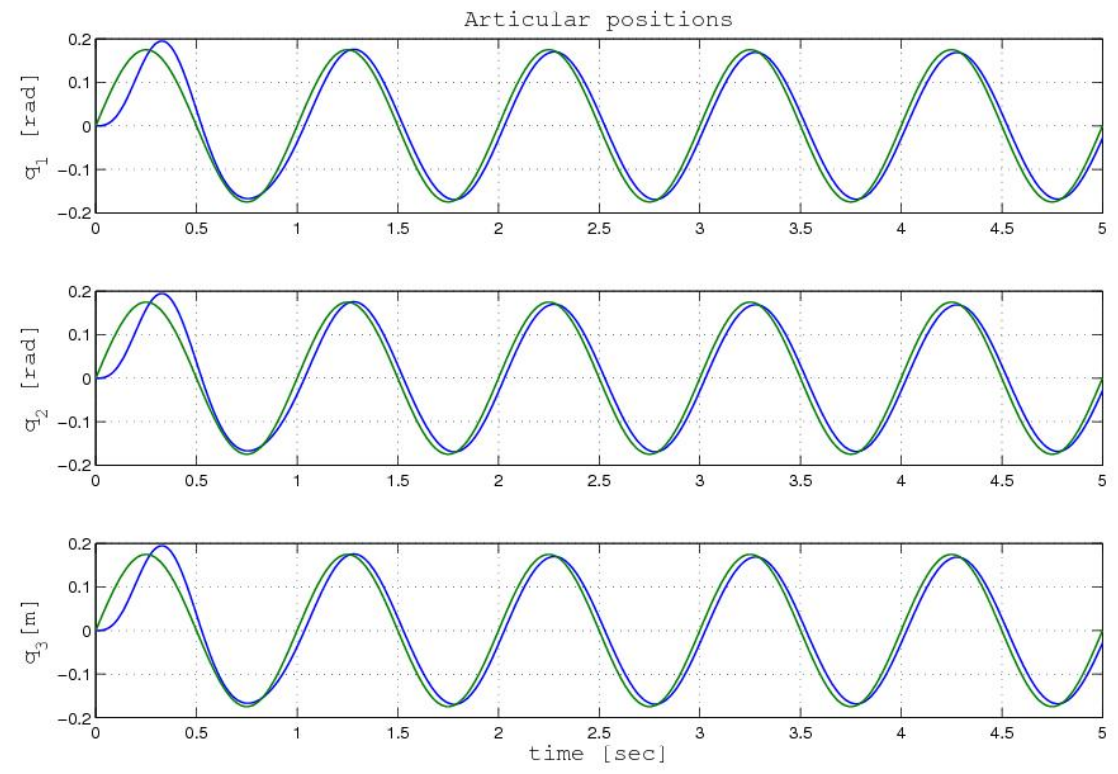

Figure 8 Control torques for the FMRAC controller with $\alpha=0.7$ (see online version for colours)
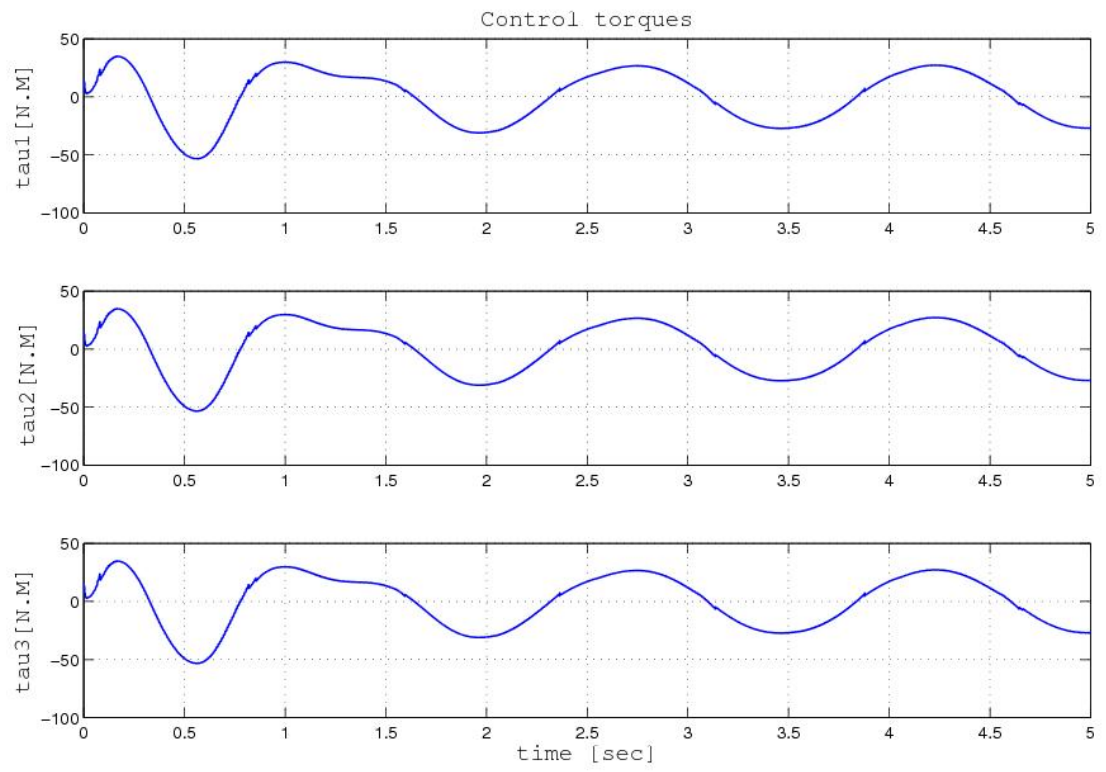
In order to search for the 'optimal' value of the fractional order $\alpha$ we measured the time delay and the overshoot of the system reference position tracking response for different values of $\alpha \in\left[\begin{array}{ll}0 & 1\end{array}\right]$. The comparative simulation results presented in Table 2, show that the system behaviour is improved for the majority of the fractional order values comparatively to the classical $(\alpha=1)$ MRAC response, and the minimal criteria are obtained for $\alpha=0.3$, as we obtain $t_{d}=0.0052 \mathrm{~s}$ and $D=0.012$.

Table 2 Comparative performance versus the model's fractional order

\begin{tabular}{ccccccccccc}
\hline$\alpha$ & 0.1 & 0.2 & 0.3 & 0.4 & 0.5 & 0.6 & 0.7 & 0.8 & 0.9 & 1 \\
\hline$t_{d}$ & 0.028 & 0.022 & 0.0052 & 0.021 & 0.027 & 0.0128 & 0.0293 & 0.0055 & 0.0277 & 0.14 \\
$D$ & 0.019 & 0.032 & 0.0120 & 0.030 & 0.019 & 0.0550 & 0.019 & 0.0118 & 0.0310 & 0.035 \\
\hline
\end{tabular}

The SCARA robot response for the best fractional order reference model $(\alpha=0.3)$, is presented in Figure 10 for the trajectory position tracking, Figure 9 for the articular speeds and Figure 11 for the input control torques.

The present study for minimising the lag between the adaptive system output and the time varying referential trajectory can be considered as a stability analysis of the robot system under FMRAC control as stabilisation problems can sometimes refer to the weak aims (Sragovich, 2006).The introduction of a fractional order model reference has indeed improved the stability and convergence of the position errors.

Figure 9 Best robot trajectory tracking using the proposed FMRAC approach with $\alpha=0.3$ (see online version for colours)
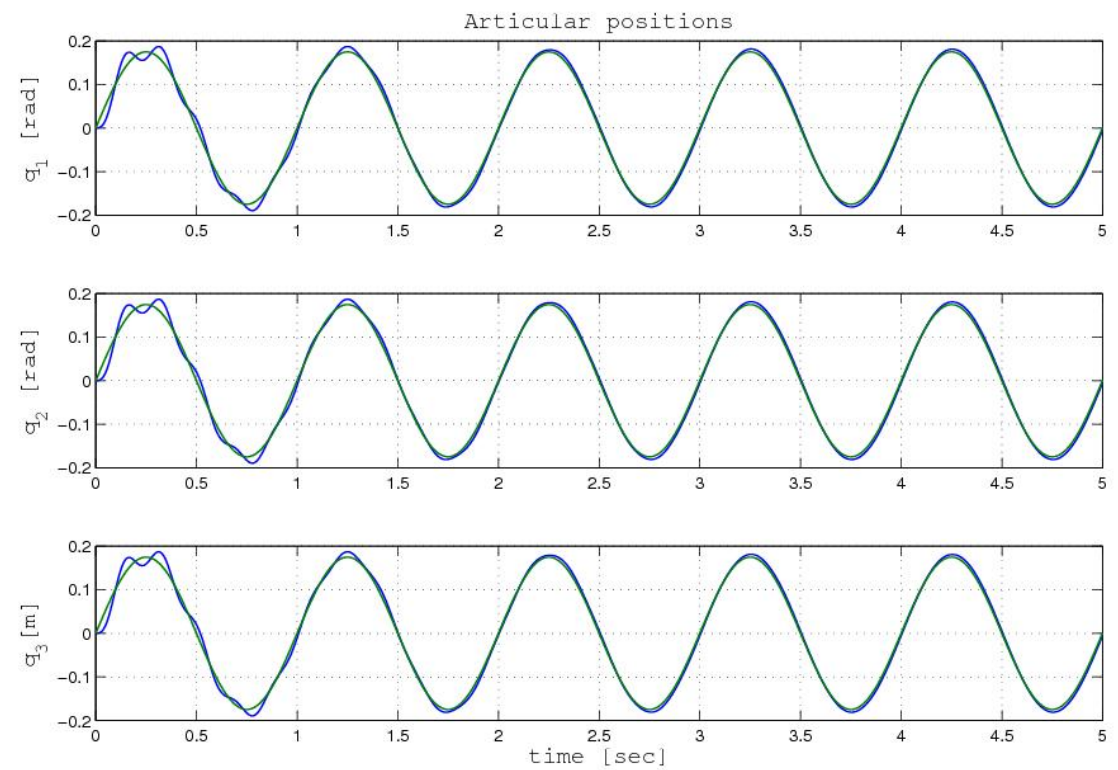
Figure 10 Articular speeds using the proposed FMRAC approach with $\alpha=0.3$ (see online version for colours)
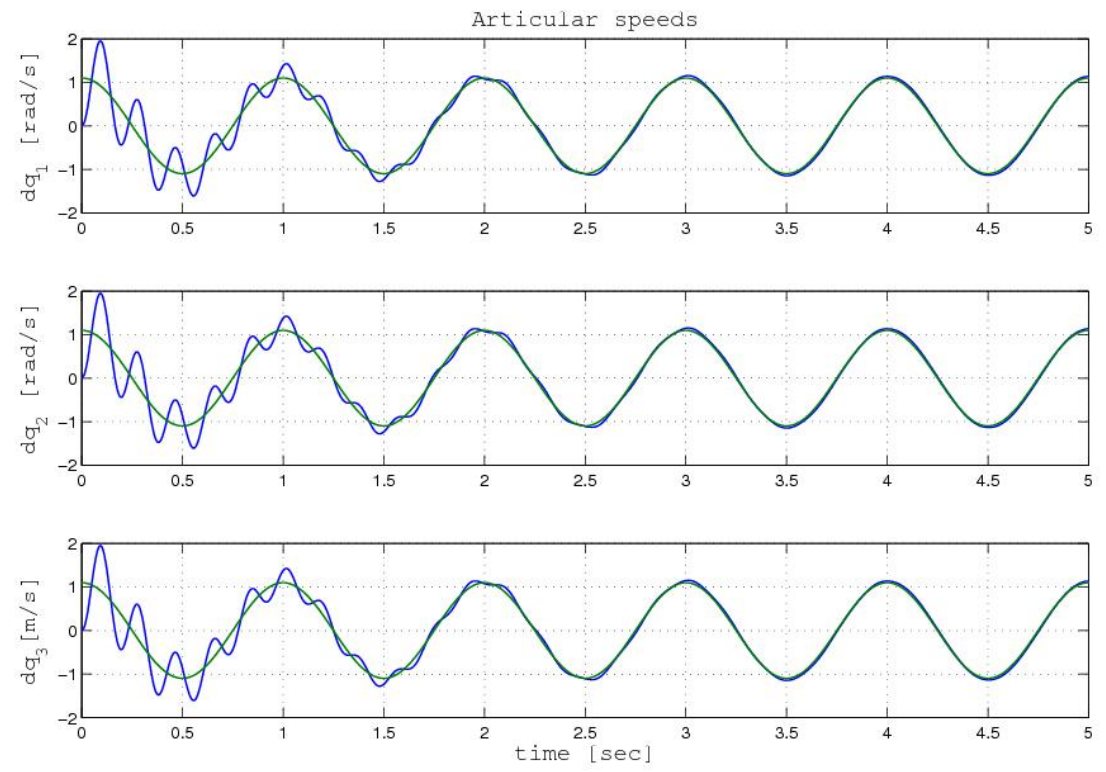

Figure 11 Control torques for the FMRAC controller with $\alpha=0.3$ (see online version for colours)
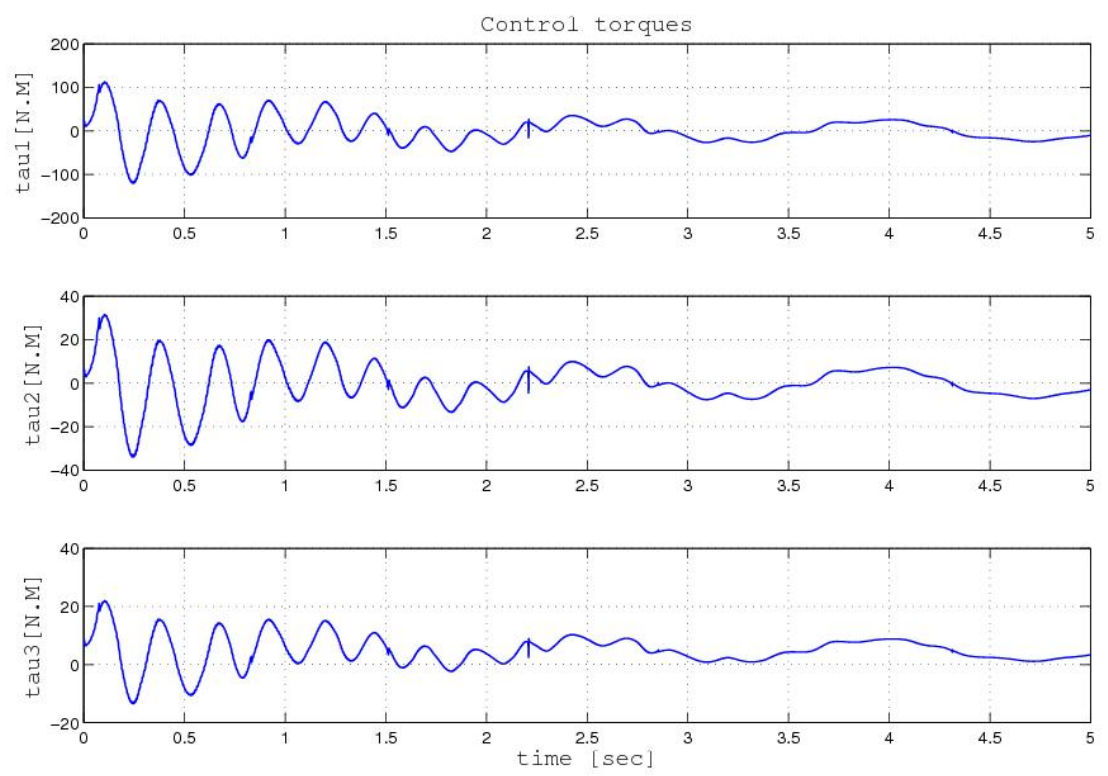


\section{Conclusions}

In this paper, the problem tackled was the time lag observed when a system tracks a varying trajectory under a MRAC. The proposed solution consists in introducing the fractional reference model in the MRAC strategy in order to eliminate the delay time and achieve a better asymptotic tracking. The idea was to get benefit from the high performance quality of fractional order systems confirmed in many precedent research works. The simulations results on a SCARA type robot manipulator show the best performances obtained by using the proposed FMRAC approach.

\section{References}

Aguila-Camacho, N. and Duarte-Mermoud, M.A. (2013) 'Fractional adaptive control for an automatic voltage regulator', ISA Trans., Vol. 52, pp.807-815.

Alonge, F., D'Ippolito, F. and Raimondi, F.M. (2003) 'An adaptive control law for robotic manipulator without velocity feedback', Control Eng. Pract., Vol. 11, pp.999-1005.

Amiri, A., Gharib, M., Moavenian, M. and Torabi, K. (2009) 'Modelling and control of a SCARA robot using quantitative feedback theory', J. Syst. Control Eng., Vol. 223.

Åström, K.J. and Wittenmark, B. (1995) Adaptive Control, Addison-Wesley, Reading, MA.

Bensafia, Y. and Ladaci, S. (2011) 'Adaptive control with fractional order reference model', Int. J. of Sciences and Techniques of Automatic Control \& Computer Engineering, IJ-STA,, Vol. 5, No. 2, pp.1614-1623.

Borenstein, J. and Koren, Y. (1987) 'Motion control analysis of a mobile robot', J. Dyn. Syst. Meas. Contr., Vol. 109, pp.73-79.

Charef, A., Sun, H.H., Tsao, Y.Y. and Onaral, B. (1992) 'Fractional system as represented by singularity function', IEEE Trans. Autom. Control, Vol. 37, 1465-1470.

Chien, C-J., Sun, K-C., Wu, A-C. and Fi, L-C. (1996) 'A robust MRAC using variable structure design for multivariable plants', Automatica, Vol. 32, No. 6, pp.833-848.

Colbaugh, R., Glass, K. and Seraji, H. (1996) 'Adaptive tracking control of manipulators: theory and experiments', Rob. Comput. Integr. Manuf., Vol. 12, No. 3, pp.209-216.

Cortesão, R. (2009) 'Model reference adaptive control for robotic manipulation with Kalman active observers', in Cong, S. (Ed.): Genetic Algorithms and Evolution Strategies in Engineering and Computer Science, pp.145-164, InTech, Croatia.

Dadras, S. and Momeni, H.R. (2010) 'Control of a fractional-order economical system via sliding mode', Physica A, Vol. 389, pp.2434-2442.

Delavari, H., Ghaderi, R., Ranjbar, N.A., HosseinNia, S.H. and Momani, S. (2010) 'Adaptive fractional PID Controller for robot manipulator', Proceedings of FDA '10, The 4th IFAC Workshop Fractional Differentiation and its Applications, Badajoz, Spain, 18-20 October.

Dumitrache, D.C., Cristian, F.E. and Inoan, I. (2012) 'A fractional order adaptive controller for a 13C cryogenic isotope separation plant', Proceedings 2012 IEEE International Conference on Automation Quality and Testing Robotics (AQTR), Cluj-Napoca, May 24-27, pp.140-143.

Dumlu, A. and Erenturk, K. (2002) 'Trajectory tracking control for a 3-DOF parallel manipulator using fractional-order $\mathrm{PI}^{\lambda} \mathrm{D}^{\mu}$ control', IEEE Trans. Ind. Electron., Vol. 61, No. 7, pp.3417-3426. 
Feng, L., Koren, Y. and Borenstein, J. (1994) 'A model-reference adaptive motion controller for a differential-drive mobile robot', Proceedings of IEEE int. Conf. on Robotics and Automation, San Diego, CA, 8-13 May, Vol. 4, pp.3091-3096.

Garg, D.P. (1991) 'Adaptive control of nonlinear dynamic SCARA type of manipulators', Robotica, Vol. 9, pp.319-326.

Hadjili, M.L. and Abida, L. (1994) 'Commande Adaptative à modéle de référence d'ordre fractionnaire (in French) (Fractional order model refrence adaptive control)', Proceedings of CMSE '94 Conference, Skikda, Algeria, 10-11 May.

Johnson Jr., C.R., Anderson, B.D.O. and Bitmead, R.R. (1984) 'A robust, locally optimal model reference adaptive controller', Proceedings of 23rd Conference on Decision and Control, Las Vegas, NV, December, pp.993-997.

Ladaci, S. and Charef, A. (2002) 'Commande adaptative à modèle de référence d'ordre fractionnaire d'un bras de robot (in French) (Fractional order model reference adaptive contol of a robot arm)', Revue Communication Sciences \& Technologie, COST, Vol. 1, pp.50-52.

Ladaci, S. and Charef, A. (2006) 'On fractional adaptive control', Nonlinear Dynamics, Vol. 43, No. 4, pp.365-378.

Ladaci, S., Loiseau, J.J. and Charef, A. (2008) 'Fractional order adaptive high gain controllers for a class of linear systems', Commun. Nonlinear Sci. Numer. Simul., Vol. 13, No. 4, pp.707-714.

Ladaci, S., Charef, A. and Loiseau, J.J. (2009) 'Robust fractional adaptive control based on the strictly positive realness condition', Int. J. Appl. Math. Comput. Sci., Vol. 19, No. 1, pp.69-76.

Ladaci, S., Loiseau, J.J. and Charef, A. (2010) 'Adaptive internal model control with fractional order parameter', Int. J. Adapt. Control Signal Process, Vol. 24, pp.944-960.

Landau, Y.D. (1979) Adaptive Control: The Model Reference Approach, Marcel Dekker, New York.

Ma, J., Yao, Y. and Liu, D. (2009) 'Fractional order model reference adaptive control for a hydraulic driven flight motion simulator', Proceedings of 41st Southeastern Symposium on System Theory, University of Tennessee Space Institute Tullahoma, TN, USA, 15-17 March, pp.340-343.

Makoudi, M. and Radouane, L. (2000) 'A robust model reference adaptive control for non-minimum phase systems with unknown or time-varying delay', Automatica, Vol. 36, pp.1057-1065.

Manabe, S. (2002) 'A suggestion of fractional-order controller for flexible', Nonlinear Dynamics, Vol. 29, pp.251-268.

Marcos, M.G., Duarte, F.B.M. and Machado, J.A.T. (2008) 'Fractional dynamics in the trajectory control of redundant manipulators', Commun. Nonlinear Sci. Numer. Simul., Vol. 13, pp.1836-1844.

Melício, R., Mendes, V.M.F. and Catalão, J.P.S. (2010) 'Fractional-order control and simulation of wind energy systems with PMSG/full-power converter topology', Energy Convers. Manage., Vol. 51, pp.1250-1258.

Neçaibia, A., Ladaci, S., Charef, A. and Loiseau, J.J. (2015) 'Fractional order extremum seeking approach for maximum power point tracking of photo-voltaic panels', Front. Energy, Vol. 9 No. 1, pp.43-53.

Neçaibia, A., Ladaci, S. and Mekhilef, S. (2015) 'ABS braking control enhancement via fractional order extremum seeking method', J. Automation Syst. Eng., Vol. 9 No. 1, pp. $23-36$. 
Oustaloup, A., Levron, F., Mathieu, B. and Nanot, F. (2000) 'Frequency-band complex non integer differentiator: Characterization and synthesis', IEEE Trans. Circuits Syst., Vol. 47, No. 1, pp.25-39.

Oustaloup, A. (1995) La Dérivation Non Entière : Théorie, Synthèse et Applications (in French), Hermès, Paris.

Pagilla, P.R. and Tomizuka, M. (2001) 'An adaptive output feedback controller for robot arms: stability and experiments', Automatica, Vol. 37, pp.983-995.

Podlubny, I. (1999) Fractional Differential Equations, Academic Press, San Diego, USA.

Roudbari, M.A. (2010) 'Design of a robust adaptive control (RAC) of robotic manipulators for trajectory tracking with structured and unstructured uncertainties', Proceedings of the World Congress on Engineering and Computer Science, WCECS0,San Francisco, USA, 20-22 October, Vol. I.

Sabatier, J., Oustaloup, A., Iturricha, A.G. and Levron, F. (2003) 'CRONE control of continuous linear time periodic systems: application to a testing bench', ISA Trans., Vol. 42, pp.421-436.

Shi, B., Yuan, J. and Dong, C. (2014) 'On fractional model reference adaptive control', The Scientific World Journal, Article ID 521625, pp.1-8.

Sragovich, V.G. (2006) Mathematical Theory of Adaptive Control, Interdisciplinary Mathematical Sciences, Vol. 4, World Scientific Publishing: New Jersey, USA.

Tung, P-C., Wang, S-R. and Hong, F-Y. (2000) 'Application of MRAC theory for adaptive control of a constrained robot manipulator', Int. J. Mach. Tools Manuf., Vol. 40, pp.2083-2097.

Vinagre, B.M., Petras, I., Podlubny, I. and Chen, Y-Q. (2002) 'Using fractional order adjustment rules and fractional order reference models in model-reference adaptive control', Nonlinear Dynamics, Vol. 29, pp.269-279.

Visioli, A. and Legnani, G. (2002) 'On the trajectory tracking control of industrial SCARA robot manipulators', IEEE Trans. Ind. Electron., Vol. 49, No. 1, pp.224-232.

Wei, Y., Sun, Z., Hu, Y. and Wang, Y. (2015) 'Robust fractional adaptive control based on the strictly positive realness condition', Int. J. Syst. Sci.

Whitcomb, L.L., Rizzi, A.A. and Koditschek, D.E. (1993) 'Comparative experiments with a new adaptive controller for robot arms', IEEE Trans. Rob. Automation, Vol. 9, No. 1, pp.59-70.

Yanling, Y. (2015) 'Model free adaptive control for robotic manipulator trajectory tracking', The Open Automation and Control Systems Journal, Vol. 7, pp.358-365.

Yildirim, S. (2005) 'Design of adaptive robot control system using recurrent neural network', J. Intell. Robot. Syst., Vol. 44, No. 3, pp.247-261. 